\title{
The Medics Role in Promoting Health Consciousness and Positive Body Image on Instagram
}

\author{
Mohammed Qureshi1 ${ }^{*}$, Rasan Burhan2 ${ }^{2}$, Raphael Olaiya ${ }^{3}$, Sohaib Imtiaz ${ }^{4}$, Ethan Smallwood ${ }^{5}$, \\ Asif Munaf6
}

${ }^{1}$ The Bradgate Mental Health Unit, Leicester, UK

${ }^{2}$ St George's University Hospitals NHS Foundation Trust, London, UK

${ }^{3}$ University College London Centre for Artificial Intelligence, London, UK

${ }^{4}$ Warrington and Halton Teaching Hospitals NHS Foundation Trust, Warrington, UK

${ }^{5}$ University of Nottingham School of Medicine, Nottingham, UK

${ }^{6}$ Sheffield, South Yorkshire, UK

Email: ^Mohammed.Qureshi@leicspart.nhs.uk

How to cite this paper: Qureshi, M., Burhan, R., Olaiya, R., Imtiaz, S., Smallwood, E. and Munaf, A. (2020) The Medics Role in Promoting Health Consciousness and Positive Body Image on Instagram. Open Access Library Journal, 7: e7060. https://doi.org/10.4236/oalib.1107060

Received: December 3, 2020

Accepted: December 28, 2020

Published: December 31, 2020

Copyright $\odot 2020$ by author(s) and Open Access Library Inc.

This work is licensed under the Creative Commons Attribution International License (CC BY 4.0).

http://creativecommons.org/licenses/by/4.0/

(c) (i) Open Access

\begin{abstract}
The exponential growth of social media over the last decade has had a dramatic impact on people's perceptions of body image. We conducted a study looking at how users feel body image has been affected by Instagram-and if medics (doctors and medical students) could aid in combatting these negative perceptions. We did this by sharing a five-part online survey over the course of 17 days. We received 113 responses in total, 80.5\% of which were from the United Kingdom, the majority (73\%) from people aged 18 - 30, with $58 \%$ of respondents being female and $42 \%$ male respectively. Our results showed that almost half $(46.3 \%)$ of females felt that Instagram negatively affected their perception of body image compared with $29.8 \%$ of males. Furthermore, the overwhelming majority of respondents, 99 (88\%), believed it would be beneficial for medics to post educational material on health and body image on Instagram. Although our study was done on a small population, it provides a starting point for further and broader explorations into how Instagram "influencers" can affect the body image perceptions of their followers-and what role medics can play in circumventing some of the more deleterious effects associated with social media use.
\end{abstract}

\section{Subject Areas}

Psychology, Public Health, Doctors, Physicians 


\section{Keywords}

Public Health, Doctors, Medicine, Social Media, Progress

\section{Introduction}

With over a billion monthly active users, Instagram has catapulted to widespread popularity since its inception a decade ago. Naturally, the population of healthcare professionals who are also Instagram users has risen at a commensurate rate. Through social media, one person alone has the ability to metaphorically become a node in a wide-reaching network, where one post can be shared on thousands of occasions in a short space of time; with the potential of positively or negatively impacting billions of people in society. Tautologically, the popularly coined terminology "social media influencer" reflects an individual's capacity to affect other people's thinking via the online community.

Since the advent of social media, the norms for how people present themselves to others have changed with images demonstrating a slim and toned physique becoming increasingly prevalent [1]. Several studies have discovered that online content can contribute to unrealistic goals for appearance and negative evaluation of self-evaluation which can lower mood and increase anxiety [2] [3] [4]. Additionally, social media not only allows people to post content, but allows others to respond. Comments in response to posted images have been demonstrated to influence the impressions formed of profile owners and the body satisfaction of observers who read the comments [5] [6]. This is highly relevant to our study, as Instagram content is largely in the form of images (with captions), another feature being comments which can be made in response to these images. Taking these points into consideration gives rise to questions pertaining to the role medical professionals have in utilising social media to promote healthy lifestyle choices and encouraging people to have positive perceptions of body image. Arguably, they have a critical role in public health awareness. Examples of promoting healthy lifestyle choices may include encouraging regular exercise, advising a balanced diet, endorsing healthy sleep patterns and recommending avoidance of significant alcohol intake, smoking and illicit substances.

The aim of our study is to determine whether it is felt by the general population that the way individuals from a medical background use Instagram plays a role in shaping perceptions of body image and in promoting good health. Furthermore, we aimed to investigate what people feel are the most effective user functions on Instagram to promote good health.

\section{Methods}

We conducted an online survey to explore this area. As well as demographic details (country of residence, gender, age, ethnicity, whether individual from medical background), the information we collated included participants views 
on whether:

- They feel Instagram has an effect on people's body perception and whether it has an effect upon their own body perception.

- Instagram influences females or males more in terms of ideas about body image.

- Instagram has had an influence on their fitness or exercise habits and an influence on their eating or dietary habits.

- They follow any medical students or doctors on Instagram, if so do these individuals post any material related to body image and what effect these posts have.

- They feel it would be beneficial for medical students/doctors to post educational material on health and body image on Instagram.

- There are any Instagram user functions that would be most effective in producing a positive impact.

We used a convenience sampling method based on participant availability and willingness to participate with full consent. The authors shared the survey with their contacts and via social media. Responses were collated over a 17-day period.

\section{Results}

We received 113 individual responses in total. 80.5\% of respondents were from the United Kingdom and the remaining participants were from 14 different countries. $58 \%$ of participants were female and $42 \%$ were male. 48 (42.5\%) were medical students or doctors, whereas 65 (57.5\%) were not. Other demographics included age (Figure 1) and ethnicity (Figure 2).

\begin{tabular}{|l|l|}
\hline Age & $\begin{array}{l}\text { Number } \\
(n)\end{array}$ \\
\hline $18-25$ & 49 \\
\hline $26-30$ & 33 \\
\hline $31-35$ & 12 \\
\hline $36-40$ & 4 \\
\hline $41-50$ & 7 \\
\hline $50+$ & 8 \\
\hline
\end{tabular}

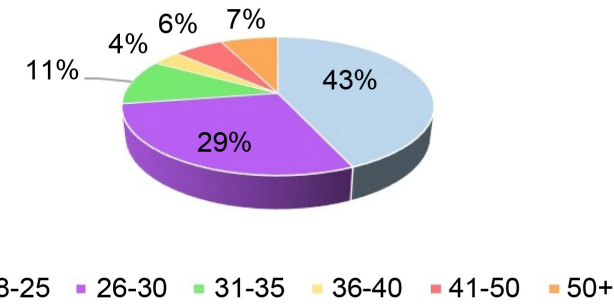

Figure 1. Age of respondents.

\begin{tabular}{|l|l|}
\hline Ethnicity & $\begin{array}{l}\text { Number } \\
(\mathrm{n})\end{array}$ \\
\hline White & 63 \\
\hline Afro-Caribbean & 11 \\
\hline Asian & 26 \\
\hline Hispanic & 1 \\
\hline Mixed & 4 \\
\hline Other & 8 \\
\hline
\end{tabular}
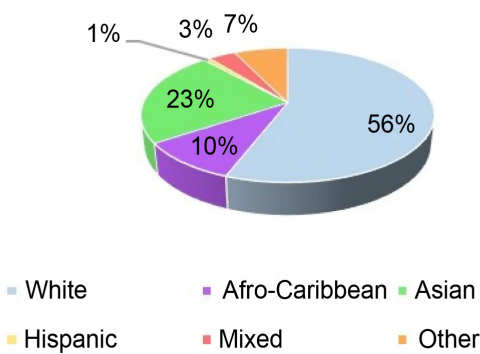

Figure 2. Ethnicity of respondents. 
With regards to individuals' views on the effect of Instagram in general on people's body perception and on their own body perception, 93 (82\%) thought that Instagram has a negative effect on people's body image and 45 (40\%) believed Instagram has a negative effect upon their own perception of body image (Figure 3).

We asked respondents if they believed there is any variability between males and females as to influence on body image, and 68 (60\%) felt females were more likely to be influenced whereas only 2 (2\%) felt males were more likely. 39 (35\%) felt both genders were equally likely to be influenced by Instagram, and the remaining 4 participants were unsure.

We then went on to ask about whether participants felt that the social media platform had influenced fitness/exercise habits and also eating/dietary habits (Figure 4).

The next area that was explored in the survey was whether the participants followed any medical students or doctors on Instagram and if so whether they post any material related to body image, and the perceived effect of such posts (Figure 5).

A key viewpoint we wanted to establish was whether participants believed it would be beneficial for medical students and doctors to post educational material or beneficial content on health and body image on the Instagram platform,

\begin{tabular}{|l|l|l|l|}
\hline \multirow{2}{*}{ Views } & \multicolumn{3}{|c|}{ Responses (n) } \\
\cline { 2 - 4 } & Positive & Negative & Neutral \\
\hline Effects on others body perception & $3(3 \%)$ & $93(82 \%)$ & $17(15 \%)$ \\
\hline Effects on their own body perception & $17(15 \%)$ & $45(40 \%)$ & $51(45 \%)$ \\
\hline
\end{tabular}

Figure 3. Views about Instagram effects on body image perception.

\begin{tabular}{|l|l|l|l|}
\hline \multirow{2}{*}{ Views } & \multicolumn{3}{|c|}{ Responses (n) } \\
\cline { 2 - 4 } & Yes & No & Unsure \\
\hline Influence on fitness or exercise habits & $64(56.5 \%)$ & $37(33 \%)$ & $12(10.5 \%)$ \\
\hline Influence on eating or dietary habits & $59(52 \%)$ & $48(42.5 \%)$ & $6(5.5 \%)$ \\
\hline
\end{tabular}

Figure 4. Views about whether Instagram influences healthy lifestyle habits (exercise and diet).

\begin{tabular}{|l|l|l|l|}
\hline & Yes & No & Unsure \\
\hline $\begin{array}{l}\text { Do you follow a medical student } \\
\text { or doctor on Instagram? }\end{array}$ & $96(85 \%)$ & $15(13 \%)$ & $2(2 \%)$ \\
\hline $\begin{array}{l}\text { Do they post any material related } \\
\text { to body image? }\end{array}$ & $54(48 \%)$ & $45(40 \%)$ & $14(12 \%)$ \\
\hline Question & Positive & Negative & Neutral \\
\hline $\begin{array}{l}\text { What effects do their posts have } \\
\text { on body image perception? }\end{array}$ & $47(42 \%)$ & $15(13 \%)$ & $51(45 \%)$ \\
\hline
\end{tabular}

Figure 5. Whether participants followed medics on Instagram and whether these medics posted beneficial content related to body image and healthy lifestyle. 
or whether they felt this would be inappropriate or unnecessary. The respondents were overwhelmingly of the view that they should, with 99 (88\%) suggesting it would be beneficial (Figure 6).

The final area that we delved into was whether there were any particular user interfaces on Instagram that participants felt would be most conducive to having a positive impact on followers' lifestyle and body perception. The results are highlighted in Figure 7.

\section{Discussion}

The present study sought to investigate people's view on whether medics (medical students and doctors) have a role to play in promoting a healthy lifestyle and positive perceptions of body image. Studies before have researched whether social media in general has an influence upon users' perception of body image and the impact of social media upon mental health, however there has been little analysis on the role of medical professionals in informing positive and healthy lifestyle choices using social media platforms.

The results of our study indicate that, as expected, the majority of people believe it would be beneficial for medics to post educational material on health and

\begin{tabular}{|l|l|}
\hline $\begin{array}{l}\text { Would it be beneficial for medics to post } \\
\text { educational material on health and body image? }\end{array}$ & $\begin{array}{l}\text { Number } \\
(\mathrm{n})\end{array}$ \\
\hline Yes & 99 \\
\hline No & 5 \\
\hline Unsure & 9 \\
\hline
\end{tabular}

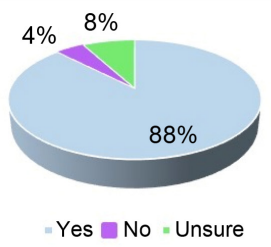

Figure 6. Whether participants believed it would be beneficial for medics on Instagram to post healthy lifestyle content.

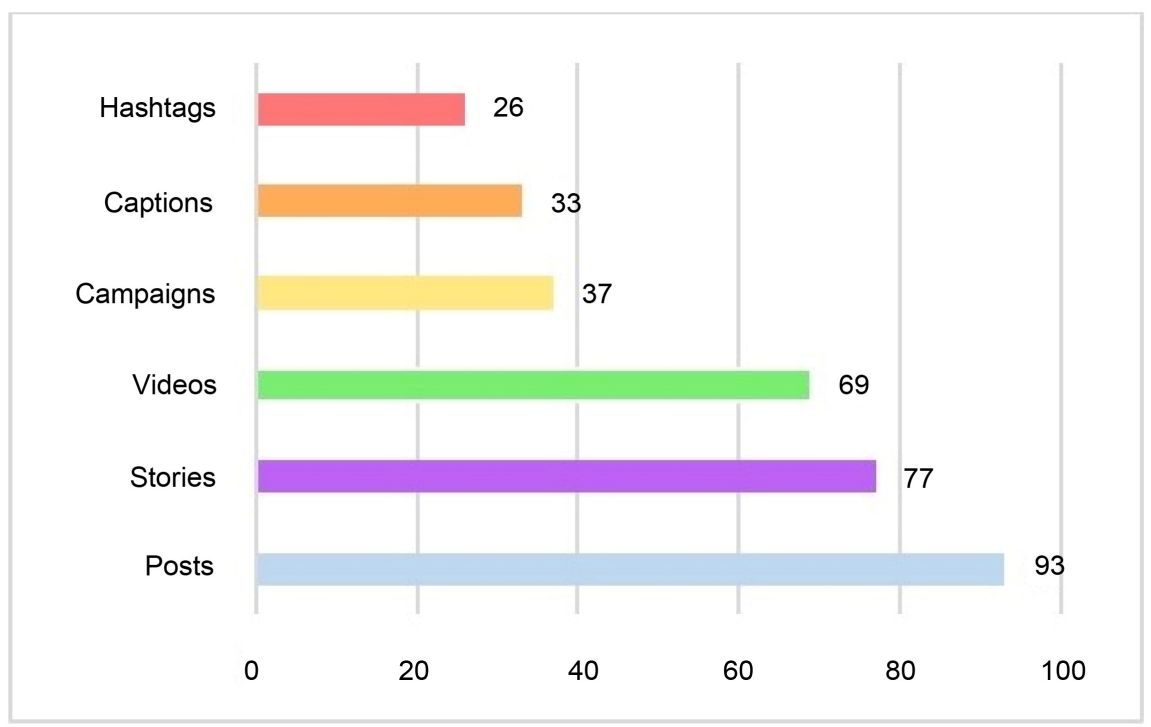

Figure 7. Instagram user functions that were deemed to be most useful for having positive impact on healthy lifestyle and body perception. 
body image, on Instagram. We can postulate that one of the reasons that people agree medics should post more educational material, is that it can have a larger impact on the population as medics are credible advisors due to their knowledge and experience in the health sciences.

With regards to gender differences, 31/67 (46.3\%) females thought that Instagram had a negative influence upon their own perception of body image, whereas 14/47 (29.8\%) males thought the same. 9/67 (13.4\%) females believed Instagram had a positive influence on perception of their body image versus $8 / 47$ (17\%) males. This suggests females have a greater proclivity to experience concerns regarding their body image due to Instagram posts, as compared to males. What is also highlighted by these results is that the positive influence of Instagram upon users' perception of their body image is low (15\%) and there is no great variability between the genders on this front. It is interesting that overall, users are more likely to feel negatively influenced by Instagram than positively when it comes to views on body image.

Limitations of our study include that a convenience sampling method was used, which makes it more likely that our study population was less representative of the whole population. Secondly, we explored the effects of Instagram on perception of body image, but there are numerous other forms of social media which may have more positive influences on healthy lifestyle. Thirdly, our survey included only closed questions, which did not allow participants to expand qualitatively upon their answers, therefore in this study we were unable to explore specific details of what the content of posts are which either positively or negatively impact perception of body image and lifestyle choices.

This study indicates that Instagram can indeed possess influence over individuals (health related) lifestyle choices and perception of body image, and that people feel medics posting educational material on these issues would be of benefit. Therefore, we would recommend that there needs to be more of an initiative and drive in educating medics who use Instagram about the importance of socially conscientious use of the platform. These could be gradually be integrated into the medical curricula to reflect the social responsibilities of doctors graduating in these modern times.

\section{Conclusions}

Social media is an instrumental tool in conveying knowledge and information to large audiences. There is a large population of medics who are users of the social media platform Instagram. Instagram is one of the most popular social media sites with over 1 billion monthly users in 2020 .

Our research suggests that a large proportion of the population feel Instagram has negative effects on people's perception of their body image rather than positive effects ( $82 \%$ vs $3 \%$ ). Individuals also feel that posts on Instagram have more of a negative effect on their own perception of body image as opposed to positive effect, but the divide is less stark ( $40 \%$ vs $15 \%$ ). The vast majority of people 
(88\%) feel that it would be beneficial for medics to post educational material regarding health and body image, on their Instagram profiles.

Social media has broader implications when it comes to mental health including disorders such as BDD. The increasing use of cosmetic procedures and expectations on social media warrants a closer analysis into this link. Body Dysmorphic Disorder (BDD) is categorised as a chronic mental illness with the inability to stop focusing on an aspect of appearance-which is perceived as a major flaw (but in reality is minor or imagined). It has been associated with many negative outcomes including a poorer quality of life, depression, social isolation and an increased suicide risk [7]. The disorder can affect many facets of life and can lead to many problems including problems at work, relationships and in the public. The excessive concern about appearance which is disproportionate in nature can cause clinically significant impairment and leads to distress in an individual's life [8].

This raises wider discussion points around how medics can utilise Instagram (and by extension, other social media platforms) to benefit society by improving awareness of healthy lifestyle choices, and how the medical community in fact has a responsibility to use social media at least in part, for this purpose. Additionally, the research highlights that a significant proportion of individuals feel that Instagram has negatively impacted their perception of body image, and so as well as advising healthy lifestyle choices it's also important for medics to abstain from posting material that may negatively impact other individual's health.

\section{Acknowledgements}

With gratitude to all participants who took part with full informed consent.

\section{Conflicts of Interest}

No conflicts of interest to declare from any author involved in study.

\section{References}

[1] Tiggemann, M. and Zaccardo, M. (2018) 'Strong Is the New Skinny': A Content Analysis of \#fitspiration Images on Instagram. Journal of Health Psychology, 23, 1003-1011. https://doi.org/10.1177/1359105316639436

[2] Holland, G. and Tiggemann, M. (2016) A Systematic Review of the Impact of the Use of Social Networking Sites on Body Image and Disordered Eating Outcomes. Body Image, 17, 100-110. https://doi.org/10.1016/j.bodyim.2016.02.008

[3] Fardouly, J. and Vartanian, L.R. (2015) Negative Comparisons about One's Appearance Mediate the Relationship between Facebook Usage and Body Image Concerns. Body Image, 12, 82-88. https://doi.org/10.1016/j.bodyim.2014.10.004

[4] Nesi, J. and Prinstein, M.J. (2015) Using Social Media for Social Comparison and Feedback-Seeking: Gender and Popularity Moderate Associations with Depressive Symptoms. Journal of Abnormal Child Psychology, 43, 1427-1438. https://doi.org/10.1007/s10802-015-0020-0

[5] Walther, J.B., Van Der Heide, B., Hamel, L.M. and Shulman, H.C. (2009) Self-Generated versus Other-Generated Statements and Impressions in Computer-Mediated Commu- 
nication: A Test of Warranting Theory Using Facebook. Communication Research, 36, 229-253. https://doi.org/10.1177/0093650208330251

[6] Tiggemann, M. and Barbato, I. (2018) "You Look Great!": The Effect of Viewing Appearance-Related Instagram Comments on Women's Body Image. Body Image, 27, 61-66. https://doi.org/10.1016/j.bodyim.2018.08.009

[7] Veale, D. (2004) Body Dysmorphic Disorder. Postgraduate Medical Journal, 80, 67-71. https://doi.org/10.1136/pmj.2003.015289

[8] Krebs, G., Fernández de la Cruz, L. and Mataix-Cols, D. (2017) Recent Advances in Understanding and Managing Body Dysmorphic Disorder. Evidence-Based Mental Health, 20, 71-75. https://doi.org/10.1136/eb-2017-102702 